\title{
BMJ Open Participant education, spousal education and dementia risk in a diverse cohort of members of an integrated health care delivery system in Northern California
}

\author{
Paola Gilsanz (D) , ${ }^{1,2}$ Elizabeth Rose Mayeda, ${ }^{3}$ Chloe W Eng, ${ }^{2}$ Oanh L Meyer, ${ }^{4}$ \\ M Maria Glymour (D) ,2 Charles P Quesenberry, ${ }^{5}$ Rachel A Whitmer ${ }^{1,6}$
}

To cite: Gilsanz P, Mayeda ER, Eng CW, et al. Participant education, spousal education and dementia risk in a diverse cohort of members of an integrated health care delivery system in Northern California. BMJ Open 2021;11:e040233. doi:10.1136/ bmjopen-2020-040233

- Prepublication history and supplemental material for this paper is available online. To view these files, please visit the journal online (http://dx.doi. org/10.1136/bmjopen-2020040233).

Received 08 May 2020 Accepted 16 May 2021

Check for updates

(C) Author(s) (or their employer(s)) 2021. Re-use permitted under CC BY-NC. No commercial re-use. See rights and permissions. Published by BMJ.

For numbered affiliations see end of article.

Correspondence to Dr Paola Gilsanz; paola.gilsanz@kp.org

\section{ABSTRACT}

Objective The role of spousal education on dementia risk and how it may differ by gender or race/ethnicity is unknown. This study examines the association between one's own education separate from and in conjunction with spousal education and risk of dementia.

Design Cohort.

Setting Kaiser Permanente Northern California (KPNC), an integrated health care delivery system.

Participants 8835 members of KPNC who were aged 40-55, married and reported own and spousal education in 1964-1973.

Primary outcome measure Dementia cases were identified through medical records from 1 January 1996 to 30 September 2017.

Methods Own and spousal education was self-reported in 1964-1973 and each was classified as four indicator variables (shigh school, trade school/some college, college degree and postgraduate) and as $\geq$ college degree versus $<$ college degree. Age as timescale weighted Cox proportional hazard models adjusted for demographics and health indicators evaluated associations between participant education, spousal education and dementia risk overall and by gender and race/ethnicity.

Results The cohort was 37\% non-white, $46 \%$ men and $30 \%$ were diagnosed with dementia during followup from 1996 to 2017 (mean follow-up=12.7 years). Greater participant education was associated with lower dementia risk independent of spousal education, demographics and health indicators. Greater spousal education was associated with lower dementia adjusting for demographics but became non-significant after further adjustment for participant education. The same pattern was seen for spousal education $\geq$ college degree (not adjusting for participant education $\mathrm{HR}$ ${ }_{\text {degree }}=0.83$ (95\% Cl: 0.76 to 0.90$)$; adjusting for participant education $\mathrm{HR}_{\text {spousal education } z \text { college degree }}=0.92(95 \% \mathrm{Cl}: 0.83$ to 1.01)). These associations did not vary by gender or race/ ethnicity.

Conclusion In a large diverse cohort, we found that higher levels of participant's own education were associated with lower dementia risk regardless of spousal education. An inverse association between spousal education and dementia risk was also present, however, the effects became non-significant after adjusting for participant education.
Strengths and limitations of this study

- This is the first study to evaluate the contributions of spousal educational attainment on dementia risk and allows its effect to vary by participant's own educational attainment, gender and race/ethnicity.

- This study follows a diverse sample of over 8800 individuals reporting own and spousal education in 1964-1973 and follows them for dementia between 1996 and 2017.

- This study adjusts for a range of health indicators prospectively collected from midlife and late-life.

- Limitations include being unable to control for duration of marriage, quality of education and childhood socioeconomic status.

- Lack of imaging data restricted the ability to examine the association between participant's own education or spousal education and markers of cognitive reserve.

\section{INTRODUCTION}

Studies repeatedly demonstrate a protective effect of one's own educational attainment on dementia risk. ${ }^{1-3}$ One hypothesised pathways linking one's own education and dementia risk include physiological changes in the brain that protect against dementia onset (ie, increased cognitive reserve). Another possible pathway that may occur concurrently is by education influencing the socioeconomic trajectory of individuals providing exposure to protective factor such as higher income, better access to high quality medical care and cognitively demanding occupations. Marital status is also associated with dementia risk such that married individuals are at lower risk of dementia than their single or widowed counterparts. ${ }^{4}$ Spousal education can provide resources at the household level that improve health outcomes for all members. For example, spousal education is inversely associated with mortality ${ }^{56}$ and positively associated with self-rated health, ${ }^{78}$ and marital status 
is associated with access to healthcare. ${ }^{910}$ Yet it remains unknown how spousal education or household level of education (ie, educational attainment of both spouses) is associated with dementia risk. No prior studies have examined the association between spousal education and dementia risk and the two studies examining its association with cognitive function had opposing results. ${ }^{11} 12$ Furthermore, it is unknown if and how one's own education, gender and race/ethnicity modify the relationship between spousal education and own dementia risk. Educational opportunities in the USA have historically varied by gender ${ }^{13}$ and race/ethnicity. ${ }^{14-18}$ The resources substitution theory ${ }^{19}$ suggests that, in the US, women and minorities would benefit more from spousal education than White men since there are barriers to them accessing education and alternative health promoting resources themselves. On the other hand, the resource multiplication theory ${ }^{2}$ suggests that White men in the US would benefit most from spousal education since they have more resources that augment the advantage provided by spousal education.

This study aims to examine the association between spousal pairs' education levels and dementia risk in a diverse cohort of over 8800 men and women who reported their own and their spouse's educational attainment. We examined the association between participants' own education, their spouse's education and education concordance within spousal pairs with dementia risk. We hypothesised that one's own education and that spousal education were inversely associated with dementia risk independent of each other. We hypothesised that resource substitution would occur and the association between spousal education and participant dementia risk would be larger among individuals with less than college degrees, and for women and minority groups that have historically had fewer educational opportunities.

\section{METHODS}

\section{Study population}

Analyses followed members of Kaiser Permanente Northern California (KPNC) who participated in the Multiphasic Health Checkups (MHC) during the 1960s1970 s between the ages of 40 and 55 years and were KPNC members as of 1 January 1996. KPNC is an integrated healthcare delivery system. The member population is generally representative of the catchment area, with the caveat that individuals at extreme tails of the income distribution are under-represented..$^{20-22}$ The MHC was an optional check-up provided to health plan members in San Francisco and Oakland, California. A total of 14696 individuals were married, 40-55 years old and reported their own sex and educational attainment, and their spouse's educational attainment at their MHC visit in the 1960s-1970s. We excluded 5861 people due to death prior to $1996(\mathrm{n}=2234)$ or lack of KPNC membership $(\mathrm{n}=3627)$ in 1996. Our final analytic dataset for the main analyses included 8835 members who were married and reported their own and their spouse's level of education.

\section{Patient and public involvement}

No patient involved.

\section{Participant and spousal education}

The 1964-1973 MHC questionnaire captured information on participant and spousal educational attainment. In separate items, participants were asked the highest grade they and their spouse completed (response options: $0-6$; 7-9; 10-11; 12; technical/business; partial college; college graduate; postgraduate). Participant and spousal educational attainment were recoded into four indicator variables ( $\leq$ high school, trade school or some college, college degree and postgraduate) as well as a binary variable with college completion as the threshold ( $\geq$ college degree vs $<$ college degree). High education was defined as at least completing a college.

Educational concordance was classified as (1) neither spouse completed college (ie, both <college), (2) participant did not completed college but spouse did (participant $<$ college and spouse $\geq$ college), (3) participant completed college but spouse did not (participant $\geq$ college and spouse <college) and (4) both spouses completed college (both $\geq$ college).

\section{Dementia diagnosis}

Dementia cases between 1 January 1996 and 30 September 2017 were identified using KPNC electronic medical records, consistent with prior studies in this population. ${ }^{23-26}$ The following International Classification of Diseases, Ninth Revision (ICD-9) and Tenth Revision (ICD-10) diagnosis codes were used to identify dementia cases: Alzheimer's disease (ICD-9: 331.0; ICD-10: G30.0, G30.1, G30.8, G30.9), vascular dementia (ICD-9: 290.4x; ICD-10: F01.5x) and other/non-specific dementia (ICD-9: 290.0, 290.1x, 290.2x, 290.3, 294.2x and 294.8; ICD-10: F03.9x). A similar set of ICD-9 codes has been shown to have a sensitivity of $77 \%$ and a specificity of $95 \%$ compared with a consensus diagnosis of dementia using medical records review, physical examination, structured interviews and a neuropsychiatric battery. ${ }^{27}$

\section{Covariates}

Demographics obtained from KPNC records include age, race/ethnicity (Asian, Black, Hispanic/Latino, White and other racial/ethnic group or missing) and gender. Health indicators from midlife and late-life were obtained from the MHC and KPNC medical records and may serve as mediators of the association between spousal education and dementia risk. The 1964-1973 MHC visit included clinical measures of blood pressure and self-reported current smoking status. Blood pressure thresholds were based on recommendations from the Seventh Report of the Joint National Committee on Prevention, Detection, Evaluation and Treatment of High Blood Pressure (JNC 7). ${ }^{28}$ Individuals were classified as hypertensive if they had diastolic blood pressure $\geq 90 \mathrm{~mm} \mathrm{Hg}$ or systolic blood 
pressure $\geq 140 \mathrm{~mm} \mathrm{Hg}$. Midlife smoking status was classified as current, prior or never smoker. Late-life stroke or diabetes occurring before dementia (each coded as yes/no) were abstracted from electronic medical records between 1 January 1996 and 1 January 1997. Missing indicators were created for individuals who were missing information related to hypertension or smoking status.

\section{Analyses}

The distributions of demographics, participant education, spousal education, education concordance and participant's lifecourse health indicators were examined overall and by participant's gender. To mitigate bias due to possible selective attrition between the $\mathrm{MHC}$ and the start of dementia follow-up in 1996, we implemented unstabilised inverse probability weights of participation truncated at the 98th percentile (online supplemental table 1) that were the product of weights for survival until 1996 and membership in KPNC in 1996. Possible predictors of survival and membership were obtained from participants' MHC visit and included age (continuous), participant's education ( $\geq$ college degree vs $<$ college degree), spousal education ( $\geq$ college degree vs <college degree), sex (female, male), race/ethnicity (Asian, black, Latino, white, other), midlife hypertension status (yes/no) and smoking status (never, prior, or current smoker or missing smoking status). To allow for the association between participant and spousal education and survival until 1996 to vary by gender and race/ ethnicity, weights were estimated separately for combination of race/ethnicity and gender. There was insufficient variability among individuals who survived to 1996 to model probability of KPNC membership in 1996 by gender and race, thus those weights were estimated among a pooled sample. Assuming no unmeasured confounding, implementing these weights accounts for differential survival until 1996, and KPNC membership in 1996. We calculated the standardised mean differences of age at MHC, participant education ( $\geq$ college degree vs $<$ college degree), spousal education ( $\geq$ college degree vs $<$ college degree), sex, race/ethnicity, midlife hypertension and midlife smoking status. The standardised mean differences were well below the threshold of $<0.25$, which may be used to represent adequate covariate balance (see online supplemental table 2 for results and definition of standardised mean difference). ${ }^{29}$ We used sets of weighted Cox proportional hazards models with age as the timescale to examine the associations of participant's educational attainment, spouse's educational attainment and spousal educational concordance with dementia risk. Individuals were followed until the first of the following occurred: death, dementia diagnosis, a lapse in KPNC membership greater than 93 days or end of study period (30 September 2017). All models also adjusted for gender and race/ethnicity. First, we estimated the association between participant's education as a four-categories and dementia risk. Second, we estimated the association of spousal education as a four-categories and dementia risk.
Third, we included participant's education and spousal education, each as four categories, in the same model. Fourth, we included participant's education and spousal education, each as four categories, in the same model with further adjustment for participant's lifecourse health indicators (midlife hypertension, midlife smoking status, late-life stroke and late-life diabetes), which are conceptualised as possible mediators. These analyses were then replicated with the binary version of participant and spousal education. Finally, we evaluated associations between spousal education concordance and dementia risk, with and without adjusting for participant's lifecourse health indicators.

Possible differences in the association between participant educational attainment, spousal educational attainment and dementia risk by gender and race/ethnicity were examined in weighted models stratified by gender or race/ethnicity. Possible effect modification by gender and race/ethnicity was also examined with interactions terms included in inverse probability weighted Cox proportional hazards models estimating the association between dementia risk and the exposure of interest, the possible modifier of interest and the interaction terms comprised of the exposure of interest and the modifier of interest (eg, four-category spousal education variable*gender). $\mathrm{P}$ values for interaction terms containing categorical versions of education variables or race/ethnicity were from joint tests and from $\chi^{2}$ tests for binary versions of education or gender.

Lastly, we replicated analyses examining the association between participant's and spousal education as a fourcategories and dementia risk, adjusting for demographics, in unweighted Cox proportional hazards models.

\section{RESULTS}

The sample was $54.4 \%$ women, $36.5 \%$ non-white, with a mean age of 47.8 years at the MHC and 12.7 years of follow-up between 1996 and 2017 (table 1). Overall $30.6 \%$ of participants and $28.5 \%$ of spouses completed college. In midlife, $42.2 \%$ of the sample reported never smoking and $41.8 \%$ reported hypertension. In late-life, $2.6 \%$ of the sample had a stroke and $11.4 \%$ had diabetes. Women were less likely than male participants to have at least a college degree $(22.9 \%$ vs $39.8 \%$, p value $<0.0001)$, more likely to have a spouse with at least a college degree $(28.7 \%$ vs $27.1 \%$, p value $=0.008)$ and less likely to be in a couple in which both members have at least a college degree $(15.5 \%$ vs $20.4 \%$, p value $<0.0001)$. During follow-up (mean=12.7 years; range: 0.01-21.7 years), $30.4 \%$ of members received a dementia diagnosis. Women and minorities other than Asians were more likely to receive a dementia diagnosis then men $(33.2 \%$ women vs $27.1 \%$ men; $\chi^{2} \mathrm{p}$ value $<0.000$ ) or Asians or Whites (27.9\% Asians, 28.6 Whites, 32.7\% Hispanics/ Latinos, $36.0 \%$ Blacks, $36.0 \%$ other racial/ethnic group; $\chi^{2}$ p value $\left.<0.0001\right)$. During follow-up, $34.8 \%$ died and $15.7 \%$ were censored due to a laspse in membership; at 
Table 1 Baseline characteristics of sample overall and by participant gender

\begin{tabular}{|c|c|c|c|}
\hline & $\begin{array}{l}\text { Women } \\
\mathrm{n}(\%)\end{array}$ & $\begin{array}{l}\text { Men } \\
\mathrm{n}(\%)\end{array}$ & $\begin{array}{l}\text { Overall } \\
\mathrm{n}(\%)\end{array}$ \\
\hline$n$ & $4808(54.4)$ & 4027 (45.6) & $8835(100)$ \\
\hline \multicolumn{4}{|l|}{ Race/ethnicity } \\
\hline White & $2970(61.8)$ & $2642(65.6)$ & $5612(63.5)$ \\
\hline Black & $987(20.5)$ & $728(18.1)$ & $1715(19.4)$ \\
\hline Hispanic/Latino & $247(5.1)$ & $200(5.0)$ & $447(5.1)$ \\
\hline Asian & $430(8.9)$ & $334(8.3)$ & $764(8.7)$ \\
\hline Other or missing & $174(3.6)$ & $123(3.1)$ & $297(3.4)$ \\
\hline Age at MHC (years; mean (SD)) & $47.9(4.2)$ & $47.6(4.3)$ & $47.8(4.2)$ \\
\hline \multicolumn{4}{|l|}{ Participant education } \\
\hline$\leq$ High school & $2201(45.8)$ & 1335 (33.2) & $3536(40.0)$ \\
\hline Trade or some college & $1504(31.3)$ & $1088(27.0)$ & $2592(29.3)$ \\
\hline College degree & $486(10.1)$ & $646(16.0)$ & $1132(12.8)$ \\
\hline Postgraduate & $617(12.8)$ & $958(23.8)$ & $1575(17.8)$ \\
\hline \multicolumn{4}{|l|}{ Spousal education } \\
\hline$\leq$ High school & $2151(44.7)$ & $1793(44.5)$ & $3944(44.6)$ \\
\hline Trade or some college & $1231(25.6)$ & $1143(28.4)$ & $2374(26.9)$ \\
\hline College degree & $672(13.1)$ & $582(14.5)$ & $1256(14.2)$ \\
\hline Postgraduate & $754(15.7)$ & $507(12.6)$ & $1261(14.3)$ \\
\hline \multicolumn{4}{|l|}{ Education concordance } \\
\hline Both $<$ college & $3025(62.9)$ & $2153(53.5)$ & $5178(58.6)$ \\
\hline Participant $\geq$ college; Spouse $<$ college & $357(7.4)$ & $783(19.4)$ & $1140(12.9)$ \\
\hline Participant $<$ college; Spouse $\geq$ college & $680(14.1)$ & $270(6.7)$ & $950(10.8)$ \\
\hline Both $\geq$ college & $746(15.5)$ & $821(20.4)$ & $1567(17.7)$ \\
\hline Diagnosed dementia & $1594(33.2)$ & $1093(27.1)$ & $2687(30.4)$ \\
\hline \multicolumn{4}{|l|}{ Midlife smoking status } \\
\hline Never smoker & $2570(53.5)$ & $1156(28.7)$ & $3726(42.2)$ \\
\hline Past smoker & $1072(22.3)$ & $1602(39.8)$ & $2671(30.3)$ \\
\hline Current smoker & $1054(21.9)$ & $1157(28.7)$ & $2211(25.0)$ \\
\hline Missing & $112(2.3)$ & $112(2.8)$ & $224(2.5)$ \\
\hline \multicolumn{4}{|l|}{ Midlife hypertension } \\
\hline Yes & $1626(33.9)$ & $2063(51.2)$ & $3689(41.8)$ \\
\hline Missing & $5(0.1)$ & $1(<0.1)$ & $6(0.1)$ \\
\hline Late-life stroke & $112(2.3)$ & $113(2.8)$ & $225(2.6)$ \\
\hline Late-life diabetes & $476(9.9)$ & $529(13.1)$ & $1005(11.4)$ \\
\hline
\end{tabular}

Percentages are column percentages.

MHC, Multiphasic Health Checkups.

the end of the study period (30 September 2017), 19.1\% of the members were alive, dementia-free and remained members of KPNC.

Participant and spousal education operationalised separately as four indicator variables each

In models separately examining participant and spousal educational attainment (each considered using the indictors for the following four levels: $\leq$ high school, trade school or some college, college degree and postgraduate), there was evidence of dose-response associations such that more education for either the participant or the spouse predicted lower dementia risk for the participant (table 2, models 1 and 2). In models including both participant and spousal educational attainment (table 2, models 3 and 4), college degree and postgraduate education for participants were associated with lower risk of dementia compared with reporting high school education or less, but spousal 
Table 2 Risk of dementia associated with participant education (four categories) and spousal education (four categories) among people married during 1964-1973 MHC

\begin{tabular}{|c|c|c|c|c|}
\hline & Model 1 & Model 2 & Model 3 & Model 4 \\
\hline$\leq$ High school & Ref & - & Ref & Ref \\
\hline College degree & $0.78(0.68-0.88)$ & - & $0.80(0.69-0.92)$ & $0.82(0.71-0.94)$ \\
\hline Postgraduate & $0.70(0.62-0.79)$ & - & $0.73(0.63-0.84)$ & $0.75(0.65-0.87)$ \\
\hline$\leq$ High school & - & Ref & Ref & Ref \\
\hline Trade school/some college & - & $0.95(0.87-1.04)$ & $1.01(0.91-1.12)$ & $1.03(0.93-1.14)$ \\
\hline College degree & - & $0.85(0.75-0.95)$ & $0.94(0.82-1.06)$ & $0.95(0.83-1.08)$ \\
\hline Postgraduate & - & $0.77(0.68-0.88)$ & $0.93(0.80-1.08)$ & $0.96(0.83-1.12)$ \\
\hline
\end{tabular}

HRs estimate by Cox proportional hazards model weighted by the inverse of the probability of being in the final analytic sample. All models adjust for age (as timescale), gender and race/ethnicity. Model 4 further adjusts for midlife hypertension, midlife smoking, late-life stroke and late-life diabetes.

MHC, Multiphasic Health Checkups.

educational attainment was not associated with participant dementia risk. There was no difference in the effect of participant or spousal educational attainment (operationalised separately as four indicator variables each) on dementia risk by participant gender (stratified analyses in online supplemental table 3 models 1-4; interaction term between participant education and participant gender $\mathrm{p}$ value $=0.62$; interaction term between spousal education and participant gender $p$ value $=0.41$ ) or participant race/ethnicity (stratified analyses in online supplemental table 3 models 1-4; interaction term between participant education and participant race/ethnicity $\mathrm{p}$ value $=0.95$; interaction term between spousal education and participant race/ ethnicity $\mathrm{p}$ value $=0.38$ ). There also was no difference in the effect of participant education on dementia risk by spousal educational attainment (each operationalised four level categorical variables: interaction term between participant education and spousal education $\mathrm{p}$ value $=0.25)$.

\section{Participant and spousal education operationalised separately as binary variables}

Examining participant and spousal high educational attainment (ie, $\geq$ college degree) separately, participant high education ( $\mathrm{HR}=0.75 ; 95 \%$ CI: 0.69 to 0.82 ) or spouse high education was associated with lower dementia risk in participants adjusting for demographics (HR=0.83; 95\% CI: 0.76 to 0.90 ; figure 1 ; online supplemental table 4 models 1 and 2). Examined concurrently, participants obtaining high education continued to be associated with lower dementia risk ( $\mathrm{HR}=0.78 ; 95 \% \mathrm{CI}: 0.71$ to 0.86$)$ but the estimated effect of spousal high education was attenuated (HR=0.92; 95\% CI: 0.83 to 1.01; online supplemental table 4 models 3 ). Effect estimates remained similar after further adjustment for midlife and late-life health indicators (online supplemental table 4 model 4). Though effect estimates for the association between participant and spousal college degree on dementia risk varied by gender and race/ethnicity (online supplemental table 4 models $1-4$ ), these differences were not significant (interaction term between participant education and participant gender $p$ value $=0.62$; interaction term between spousal education and participant gender $\mathrm{p}$ value $=0.41$; interaction term between participant education and participant race/ethnicity $\mathrm{p}$ value $=0.96$; interaction term between spousal education and participant race/ethnicity $\mathrm{p}$ value $=0.38$ ). There also was no difference in the effect of participant education on dementia risk by spousal educational attainment (each operationalised as binary variables; interaction term between participant education and spousal education $\mathrm{p}$ value $=0.25$ ) .

\section{Concordance between participant and spousal education}

In demographic-adjusted models examining education concordance, with participants in couples where neither spouse completed college as the reference, participants in couples where both spouses completed college had $30 \%$ lower risk of dementia (HR=0.70; $95 \%$ CI: 0.62 to 0.78 ; online supplemental table 5 model 1). Participants in couples where the participant had completed college but the spouse had not had $17 \%$ lower risk of dementia $(\mathrm{HR}=0.83 ; 95 \%$ CI: 0.73 to 0.94$)$, while participants in couples in which the participant had not completed college but the spouse had did not have any protection from dementia (HR=0.97; 95\% CI: 0.86 to 1.09$)$. Among participants who had completed college, participants with spouses who also had completed college were at lower risk of dementia (HR=0.84; 95\% CI: 0.72 to 0.99$)$. Effect estimates were slightly attenuated after further adjustment 


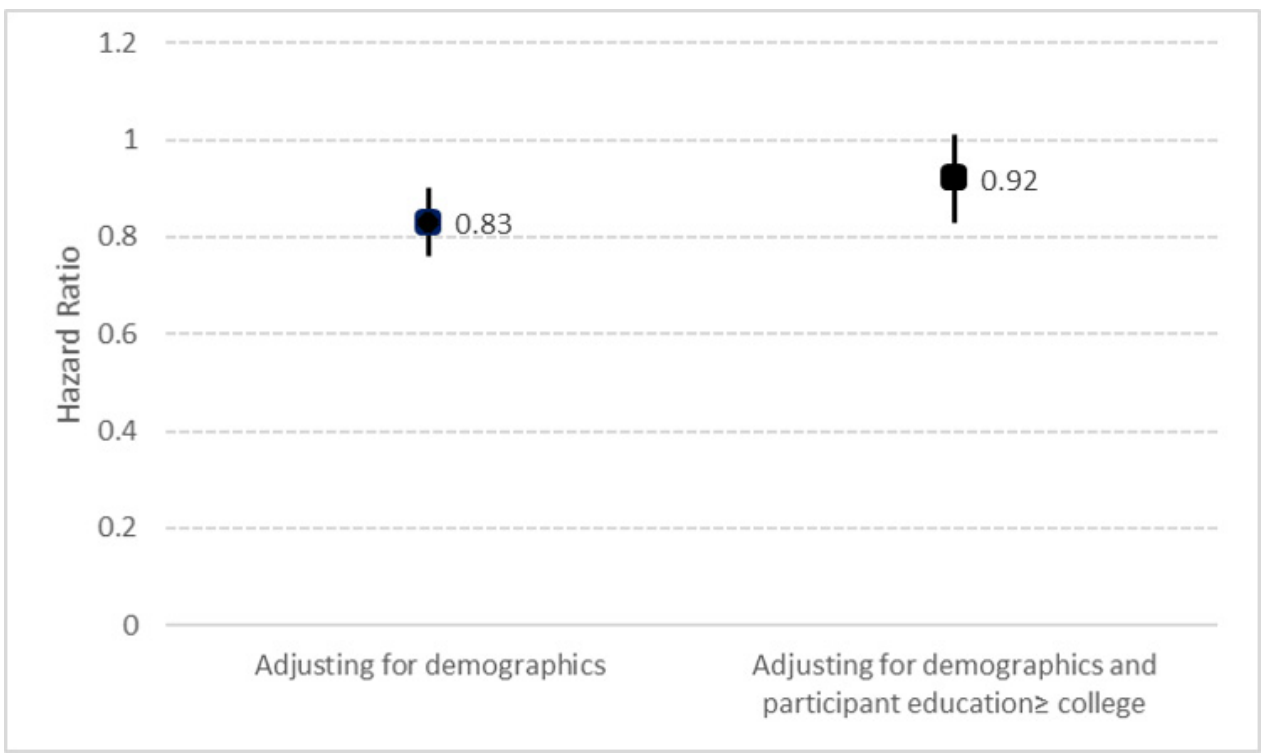

Figure 1 Risk of dementia associated with a spouse having at least college degree among people married during 1964-1973 MHC. Model 1 shows the HR associated with a spouse having at least a college degree adjusting for participant age, race/ ethnicity and gender. Model 2 further adjusts for the individual's own educational attainment (at least college degree vs less than college). MHC, Multiphasic Health Checkups.

for midlife and late-life health indicators (online supplemental table 3 model 2) and there was no additional benefit of spousal college degree among participants who completed college (HR=0.86; $95 \%$ CI: 0.73 to 1.00$)$. Though effect estimates for the different categories of education concordance varied by participant gender and race/ethnicity (online supplemental table 5 stratified analyses models 1-2), the differences in effect by gender or race/ethnicity were not significant (interaction term between education concordance and participant gender $p$ value $=0.75$; interaction term between education concordance and participant race/ethnicity $\mathrm{p}$ value $=0.71$ ).

\section{Unweighted models: participant and spousal education operationalised separately as four indicator variables each}

As in weighted models, in unweighted models separately examining participant and spousal educational attainment, there was an inverse dose-response association between both participant and spousal education and dementia risk (online supplemental table 6 models 1 and 2). In unweighted models including both participant and spousal educational attainment (online supplemental table 6 models 3), participants college degree and postgraduate education was associated with lower participant dementia risk, but spousal educational attainment was not associated with participant dementia risk.

\section{DISCUSSION}

In a large, diverse, longitudinal study, we found that higher levels of participant's own education were associated with lower dementia risk regardless of spousal education, demographics and health indicators. An inverse association between spousal education and dementia risk was also present independent of participant demographics, however, the effects became non-significant after adjusting for participant education.

Contrary to our hypotheses based on the resource substitution, we did not find evidence that the effect of spousal education was modified by participant's education, gender or race/ethnicity. Though effect estimates varied somewhat by gender and race/ethnicity, none of the differences in estimated effects were statistically significantly.

Though prior research has not examined the association between education concordance and dementia risk, our findings are consistent with a prior study demonstrating a protective effect of spousal education on late-life cognitive outcomes. ${ }^{11}$ A study using data from 5846 men and women participating in the Health and Retirement Study, a nationally representative study of non-institutionalised US adults at least age 50 and their spouses, found that greater years of spousal education were associated with higher respondent cognitive level at age 65 as well as a slower rate of cognitive decline over an 18-year period. ${ }^{11}$ The association between spousal education and respondent cognitive decline persisted after adjustment for markers of adult socioeconomic status (ie, household wealth and income), but the association between cognitive level at age 65 and spousal education was attenuated after adjustment for these potential mediators. There was no evidence of effect modification of the relationship between spousal education and late-life cognitive outcome by gender. On the other hand, in a study of 19319 female nurses at least 70 years old, husband's education was not associated with participant's risk of being in the bottom 10th percentile of baseline global cognition adjusting for women's age and own education. ${ }^{12}$ Similarly, husband's education was not associated with whether a woman 
experienced substantial cognitive decline (ie, top 10th percentile in decline) during the 2-year follow-up period.

If causal, higher spousal education may reduce dementia risk through higher levels of household resources (eg, income), cognitive stimulation derived from spouse's education or better health behaviours related to cardiometabolic health. For example, having a more educated spouse has been associated with higher levels of physical activity ${ }^{30}$ and inversely associated with smoking. ${ }^{7}$ Both low income ${ }^{31}$ and poor cardiometabolic health indicators ${ }^{24} 25$ 32-34 have been associated with greater dementia risk. However, adjusting for midlife blood pressure and smoking, and late-life diabetes and stroke did not change the relationship between spousal education concordance and dementia risk.

Overall, these findings show that one's own education is more relevant than one's spouse's education for lower dementia risk. This is consistent with education primarily protecting against dementia risk through physiological changes in the brain that protect against dementia onset (ie, increased brain or cognitive reserve) such as increased number of synapses, brain size and redundant neuronal networks. ${ }^{35}$ Individuals with high educational attainment would have greater cognitive reserve and therefore would present with fewer clinical signs of dementia than their counterparts with low cognitive reserve with the same amount of pathology. ${ }^{36}$ For example, among individuals with similar severity of clinical symptoms of Alzheimer's disease, those participants with high levels of education had more severe reductions in regional cerebral blood flow, reflecting greater Alzheimer's disease pathology, than those with lower levels of education. ${ }^{37}$

To our knowledge this is the first study to investigate the association between spousal education, spousal education concordance and dementia risk. These analyses accounted for differential selection into our analytic sample by implementing inverse probably weights estimated within sex and race/ethnicity specific groups. However, the possibility of residual selection bias remains if there are additional predictors of survival and KPNC membership in 1996 that are associated with dementia risk. High membership stability in this diverse cohort allows us to adjust for a range of covariates prospectively during midlife to late-life. Some limitations include being unable to control for duration of marriage and quality of education, which has been shown to better predict cognitive decline than years of formal education. ${ }^{38}$ This may be particularly pertinent for gender differences in college education, if men and women in these generations systematically pursued different training in college. We were unable to identify spousal pairs in which both spouses are included as participants in this study and therefore cannot account for interdependence of these observations. Lack of imaging data restricted our ability to examine the association between participant's education, spousal education and education concordance with markers of cognitive reserve. Unmeasured confounding (eg, by childhood socioeconomic status) could contribute to observed associations. We may have been underpowered to detect differences by race/ethnicity and gender, thus confirming our results in large, diverse, independent data sets is critical. There may be undiagnosed cases of dementia. Assuming spousal education is inversely associated with participant dementia risk, the associations between spousal education and participant dementia risk would be underestimated if undiagnosed dementia were more common among participants with married to spouses with lower levels of education. It is unclear whether these results are generalisable to individuals who were born during a different time periods since there are secular trends in education obtainment and quality.

Our findings build on prior work examining the association between one's own education and dementia risk by including spousal education and allowing the effect of spousal education to vary by one's own education, gender or race/ethnicity. Our findings suggest that one's own educational attainment is more relevant to dementia risk than spousal educational attainment. Additional research is needed examining the association between spousal education and one's own dementia risk and, if causal, should consider possible physiological, behavioural and socioeconomic mediators of the relationship.

\section{Author affiliations}

${ }^{1}$ Behavioral Health and Aging, Kaiser Permanente Division of Research, Oakland, California, USA

${ }^{2}$ Department of Epidemiology \& Biostatistics, University of California San Francisco, San Francisco, California, USA

${ }^{3}$ Department of Epidemiology, University of California Los Angeles Fielding School of Public Health, Los Angeles, California, USA

${ }^{4}$ Department of Neurology, University of California Davis, Davis, California, USA ${ }^{5}$ Biostatistics Core, Kaiser Permanente Division of Research, Oakland, California, USA

${ }^{6}$ Department of Public Health Sciences, University of California Davis, Davis, California, USA

Twitter Paola Gilsanz @PaolaGilsanz

Contributors PG contributed to planning, data acquisition, analyses, data interpretation, manuscript preparation; ERM, CWE, OLM, MMG, CPQ, RAW contributed to planning, data interpretation, manuscript revision.

Funding This study was supported by grants from the National Institute on Ageing (RF1AG052132 (Multiple PI: RAW, MMG, Mungas), R01AG066132 (PI: PG), R00AG053410 (Pl: ERM), P30AG010129 (PI: OLM), K01AG052646 (PI: OLM), RF1AG056519 (PI: RAW), RF1AG050782 (Multiple PI: RAW, Corrada)), the Alzheimer's Association/The Judy Fund (2019-AARGD-644788 (PI: PG)) and the Alzheimer's Association (AARGD 19-6 19832 (PI: OLM)).

Competing interests None declared.

Patient consent for publication Not required.

Ethics approval This study was approved by the KPNC Internal Review Board (CN-16-2786-05)

Provenance and peer review Not commissioned; externally peer reviewed.

Data availability statement Data are available upon reasonable request. The data used in this study are held by Kaiser Permanente Northern California (KPNC) Division of Research. Researcher interested in collaborating with KPNC and accessing these data can submit an application through the Research Collaboration Portal at https://rcp.kaiserpermanente.org/.

Supplemental material This content has been supplied by the author(s). It has not been vetted by BMJ Publishing Group Limited (BMJ) and may not have been peer-reviewed. Any opinions or recommendations discussed are solely those of the author(s) and are not endorsed by BMJ. BMJ disclaims all liability and 
responsibility arising from any reliance placed on the content. Where the content includes any translated material, BMJ does not warrant the accuracy and reliability of the translations (including but not limited to local regulations, clinical guidelines, terminology, drug names and drug dosages), and is not responsible for any error and/or omissions arising from translation and adaptation or otherwise.

Open access This is an open access article distributed in accordance with the Creative Commons Attribution Non Commercial (CC BY-NC 4.0) license, which permits others to distribute, remix, adapt, build upon this work non-commercially, and license their derivative works on different terms, provided the original work is properly cited, appropriate credit is given, any changes made indicated, and the use is non-commercial. See: http://creativecommons.org/licenses/by-nc/4.0/.

\section{ORCID iDs}

Paola Gilsanz http://orcid.org/0000-0002-7635-381X

M Maria Glymour http://orcid.org/0000-0001-9644-3081

\section{REFERENCES}

1 Stern Y, Gurland B, Tatemichi TK, et al. Influence of education and occupation on the incidence of Alzheimer's disease. JAMA 1994;271:1004-10.

2 Caamaño-Isorna F, Corral M, Montes-Martínez A, et al. Education and dementia: a meta-analytic study. Neuroepidemiology 2006;26:226-32.

3 Marden JR, Tchetgen Tchetgen EJ, Kawachi I, et al. Contribution of socioeconomic status at 3 life-course periods to late-life memory function and decline: early and late predictors of dementia risk. Am J Epidemiol 2017;186:805-14.

4 Sommerlad A, Ruegger J, Singh-Manoux A, et al. Marriage and risk of dementia: systematic review and meta-analysis of observational studies. J Neurol Neurosurg Psychiatry 2018;89:231-8.

5 Spoerri A, Schmidlin K, Richter M, et al. Individual and spousal education, mortality and life expectancy in Switzerland: a national cohort study. J Epidemiol Community Health 2014;68:804-10.

6 Jaffe DH, Eisenbach Z, Neumark YD, et al. Effects of husbands' and wives' education on each other's mortality. Soc Sci Med 2006;62:2014-23.

7 Monden CWS, van Lenthe F, de Graaf ND, et al. Partner's and own education: does who you live with matter for self-assessed health, smoking and excessive alcohol consumption? Soc Sci Med 2003;57:1901-12.

8 Brown DC, Hummer RA, Hayward MD. The importance of spousal education for the self-rated health of married adults in the United States. Popul Res Policy Rev 2014;33:127-51.

9 Meyer $\mathrm{MH}$, Pavalko EK. Family, work, and access to health insurance among mature women. J Health Soc Behav 1996;37:311-25.

10 Ponce NA, Cochran SD, Pizer JC, et al. The effects of unequal access to health insurance for same-sex couples in California. Health Aff 2010;29:1539-48.

$11 \mathrm{Xu}$ M. Spousal education and cognitive functioning in later life. J Gerontol B Psychol Sci Soc Sci 2020;75:e141-50.

12 Lee S, Kawachi I, Berkman LF, et al. Education, other socioeconomic indicators, and cognitive function. Am J Epidemiol 2003;157:712-20.

13 Madigan JC. The education of women and girls in the United States: a historical perspective. Adv Gender Educ 2009;1:11.

14 Ryan CL, Bauman K. Educational attainment in the United States $2016 ; 2015$.

15 Ortiz V, Telles E. Racial identity and racial treatment of Mexican Americans. Race Soc Probl 2012;4:41-56.

16 John L, Deirdre O, Jacob S. Resegregation in U.S. public schools or white decline? A closer look at trends in the 1990s. Child Youth Environ 2006;16:49-68.
17 Clotfelter CT. Private schools, segregation, and the southern states. Peabody J Educ 2004;79:74-97.

18 Kimbro RT, Bzostek S, Goldman N, et al. Race, ethnicity, and the education gradient in health. Health Aff 2008;27:361-72.

19 Ross CE, Mirowsky J. Sex differences in the effect of education on depression: resource multiplication or resource substitution? Soc Sci Med 2006;63:1400-13.

20 Gordon NP, Kaplan GA. Some evidence refuting the HMO "favorable selection" hypothesis: the case of Kaiser Permanente. Adv Health Econ Health Serv Res 1991;12:19-39.

21 Krieger N. Overcoming the absence of socioeconomic data in medical records: validation and application of a census-based methodology. Am J Public Health 1992;82:703-10.

22 Gordon NP. Similarity of the Kaiser Permanente senior member population in northern California to the non-Kaiser Permanente covered and general population of seniors in northern California: statistics from the 2009 California health interview survey. Oakland, CA: Kaiser Permanente Northern California Division of Research, 2012.

23 Mayeda ER, Glymour MM, Quesenberry CP, et al. Inequalities in dementia incidence between six racial and ethnic groups over 14 years. Alzheimers Dement 2016;12:216-24.

24 Whitmer RA, Sidney S, Selby J, et al. Midlife cardiovascular risk factors and risk of dementia in late life. Neurology 2005;64:277-81.

25 Gilsanz P, Mayeda ER, Glymour MM, et al. Female sex, early-onset hypertension, and risk of dementia. Neurology 2017;89:1886-93.

26 Gilsanz P, Mayeda ER, Glymour MM, et al. Association between birth in a high stroke mortality state, race, and risk of dementia. JAMA Neurol 2017;74:1056-62.

27 Katon WJ, Lin EHB, Williams LH, et al. Comorbid depression is associated with an increased risk of dementia diagnosis in patients with diabetes: a prospective cohort study. J Gen Intern Med 2010;25:423-9.

28 Chobanian AV, Bakris GL, Black HR, et al. Seventh report of the joint National Committee on prevention, detection, evaluation, and treatment of high blood pressure. Hypertension 2003;42:1206-52.

29 Stuart EA. Matching methods for causal inference: a review and a look forward. Stat Sci 2010;25:1-21.

30 Lidfeldt J, Li TY, Hu FB, et al. A prospective study of childhood and adult socioeconomic status and incidence of type 2 diabetes in women. Am J Epidemiol 2007;165:882-9.

31 Yaffe K, Falvey C, Harris TB, et al. Effect of socioeconomic disparities on incidence of dementia among biracial older adults: prospective study. BMJ 2013;347:f7051.

32 Strachan MWJ, Reynolds RM, Marioni RE, et al. Cognitive function, dementia and type 2 diabetes mellitus in the elderly. Nat Rev Endocrinol 2011;7:108-14.

33 Cheng $\mathrm{G}$, Huang $\mathrm{C}$, Deng $\mathrm{H}$, et al. Diabetes as a risk factor for dementia and mild cognitive impairment: a meta-analysis of longitudinal studies. Intern Med J 2012;42:484-91.

34 Zhang J, Chen C, Hua S, et al. An updated meta-analysis of cohort studies: diabetes and risk of Alzheimer's disease. Diabetes Res Clin Pract 2017;124:41-7.

35 Stern Y. What is cognitive reserve? Theory and research application of the reserve concept. J Int Neuropsychol Soc 2002;8:448-60.

36 Stern Y. Cognitive reserve in ageing and Alzheimer's disease. Lancet Neurol 2012;11:1006-12.

37 Stern Y, Alexander GE, Prohovnik I, et al. Inverse relationship between education and parietotemporal perfusion deficit in Alzheimer's disease. Ann Neurol 1992;32:371-5.

38 Manly JJ, Schupf N, Tang M-X, et al. Cognitive decline and literacy among ethnically diverse elders. J Geriatr Psychiatry Neurol 2005;18:213-7. 